\title{
Design and Development of a High-and-Low-Altitude Air Observation System for Rainmaking Process in Thailand
}

\author{
P. Chodkaveekityada and P. Wardkein
}

\begin{abstract}
Thailand has been known as a top agricultural exporter in the world. But in every year, we miss a lot of opportunities to export some agricultural products due to drought condition. In the years 2017 and 2018, the areas in risk of a drought crisis were 47 areas throughout the whole country amounting to around 1.5 million acres. There was not enough water to grow plants in these areas. As a matter of fact, Thailand is located near the equator which has more cumulative rainfall volume than any other areas in the world. Still, drought crisis happens every year. One of the reasons behind this may be lack of valid predictive information. Weather information is very important for an agricultural country. Thailand has not invested sufficiently in building an effective weather sensor network. A compromise has been made by employing high technology to produce rain in specific areas instead to alleviate drought crisis. This work was a design and development of a high-and-low-altitude air observation system suitable for rainmaking process in Thailand that aimed to reduce the import of advanced and expensive technology.
\end{abstract}

Index Terms - Rainmaking, high-and-low altitude air observation, ground station.

\section{INTRODUCTION}

Currently, technology has changed very rapidly. In the past, the gap of transitional change was about 10 years, but nowadays, 2 years is considered quite long for a new technology. Thailand is one country that imports most technologies from developed countries and cannot produce many technological products on its own. It is one of the reasons why Thailand cannot step forward to be a developed country. Most import technologies have been designed for general global usage, but for some of our purposes, a specific kind of technology is required. If we do not develop a know-how on how to produce a specifically needed technology, it is equivalent to the country stepping backward. We will continually need to a lot more money to buy the technology from other countries. Now is the right time to develop, adapt and apply current technologies for use within our country. At the very least, if we can acquire some know-how, we will be a smarter buyer and we can apply the know-how to conduct some immediate missions to protect the lives and assets of the people such as the recent case of Tam-Luang cave rescue.

Nowadays, sensor network system has made our life easier

Manuscript received January 6, 2019; revised April 28, 2019.

P. Chodkaveekityada and P. Wardkein are with the King Mongkut's Institute of Technology Ladkrabang, Bangkok, 10520, Thailand (e-mail: peeramed.ch@kmitl.ac.th). such as its uses in smart city, health monitoring and IoT. Agriculture is another area that follows this trend called smart farming. For smart farming, many sensors will be used for monitoring the growth of plants, for providing weather information and for automating agricultural machine operation. Sensor network will help increase the quality of agricultural products and help to manage the overall agricultural system. At present, a sensor network for farming process, for predicting the rain and for managing water for farming is very much in need. Thailand produces a lot of agricultural products to serve the world such as rice, fruits and vegetables, but we also face a lot of problem of drought and water resource management to efficiently provide water to farmers. To deal with this issue, the department of royal rainmaking and agricultural aviation was established so that farmers can grow plants throughout the year.

The weather observation system technology in Thailand was imported several decades ago. The technology that supports rainmaking is known as a radiosonde [1]-[7] system for observing the weather of the upper-air. A radiosonde system includes many subsystems such as a communication subsystem, an electrical power subsystem, and a sensor subsystem. Every subsystem was designed as a general-purpose module that is easily applied to any commercial applications. However, sometimes we need more kinds of information from a radiosonde other than temperature, pressure, and humidity that a general radiosonde provides. For example, the information on its location and its remaining battery life during an operation is very important for many of our expected operations. This research aimed to improve a radiosonde so that it can support suitable replaceable subsystems for a specific mission, not only for a conventional observation by balloon flight. For example, it was desirable to be able to attach a radiosonde to a drone, a UAV, or an airplane. Moreover, it was also desirable to be able to get personalized weather information for an individual's home from a radiosonde.

The conventional ground system for radiosonde uses a very big antenna hence needs a lot of space. This is a waste of resource and budget. This conventional system is very old. New technology is released every day and it can be used to gain more precise weather information for efficient rainmaking operation. Therefore, the ground station needs to be improved to support an advanced sensor network in the future.

Ground station design [8]-[12] is quite dependent of the specific purpose of the application. Several factors need to be considered such as operating frequency, antenna gain, operating distance and type of antenna. For our purpose, we would like to develop a ground station not only for using with 
a weather sensor network for rainmaking process but also for general weather observation. Our design was up-to-date and would be able to support any advanced sensor network. Specifically, our ground station was designed to reduce the weight of the tracking system and antenna to make it portable and easy to installed. Moreover, this paper also proposes to develop a radiosonde, a portable sensor and radio transmitter system, to be more effective than the existing system in order to better serve a variety of weather observation missions.

\section{SYSTEM DESIGN}

\section{A. Radiosonde}

A radiosonde is an instrument for weather observation [13], [14] which includes sensors and a radio transmitter. In order to develop an equipment like radiosonde, its main subsystems should be considered: the sensor subsystem and the electrical subsystem which is described below.

\section{1) Sensor subsystem}

Normally, weather observation sensors include plain temperature, pressure and humidity sensors, but our design aimed to improve the system to be more intelligent than the existing one. Fig. 1 shows our sensor subsystem that included a GPS sensor, an accelerometer sensor and a power monitor device. A microcontroller was used to create packages of formatted data that are uniquely identifiable in order to avoid interfering with other packages. Moreover, we installed a data logger to record and store all sensor data in case data loss happens while the system is in operation. The transmitter we used was a LoRa module [15]-[18] due to its long operational range of over $20 \mathrm{~km}$.

\section{2) Electrical subsystem}

This system is quite important because the its power supply has to generate sufficient power to cover all operations at all time. There were several sensors that needed a lot of power and current in order to work adequately. We selected to use a rechargeable 9V $800 \mathrm{mAh}$ battery that could supply continuous power for more than 2 hours. Fig. 2 shows the electric flow of the electrical subsystem from the source to every device. Since each device needed a maximum supply voltage of $5 \mathrm{~V}$, we had to convert the voltage down from $9 \mathrm{~V}$ to $5 \mathrm{~V}$ efficiently. Moreover, some device could use the power supplied from microcontroller ports that produced about $3.3 \mathrm{~V}$.

Fig. 3 shows the designed weather observation instrument including all of the sensors mentioned that could transmit data back to a base station with a LoRa module operating at 433 $\mathrm{MHz}$. We attached a strip of sticker to the instrument with detailed information for anyone who happened to collect it to understand its purpose and not feel panic. Moreover, we employed a parachute to reduce the descent rate as the instrument was falling down to the ground.

\section{B. Ground Station}

Ground station is design based on the mission of the operation. This project aimed to design and develop a ground station for receiving the weather information from a transmitter high up in the air that is going to be used in rainmaking operation. The altitude of the transmitter operation is between $1 \mathrm{~km}$ to $15 \mathrm{~km}$ high because the transmitter has to be at about the same height from the ground as the airplane that carries out the rainmaking operation does, not exceeding $10 \mathrm{~km}$ in height. Thus, this system must be able to operate at a height that is higher than the standard equipment typically does.

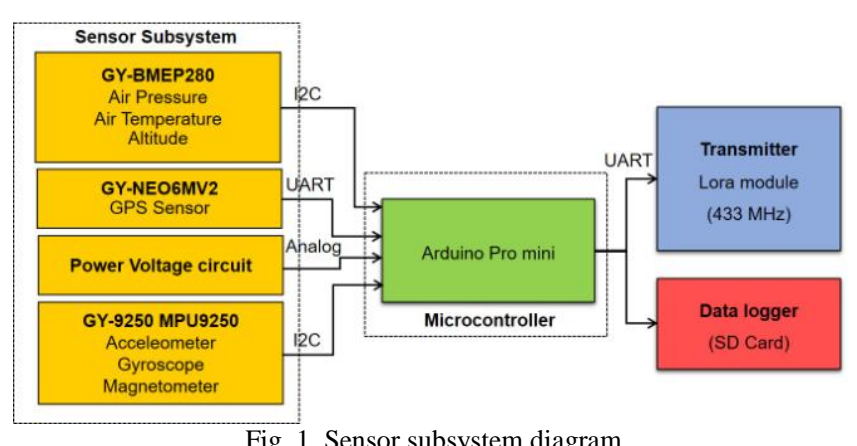

Fig. 1. Sensor subsystem diagram.

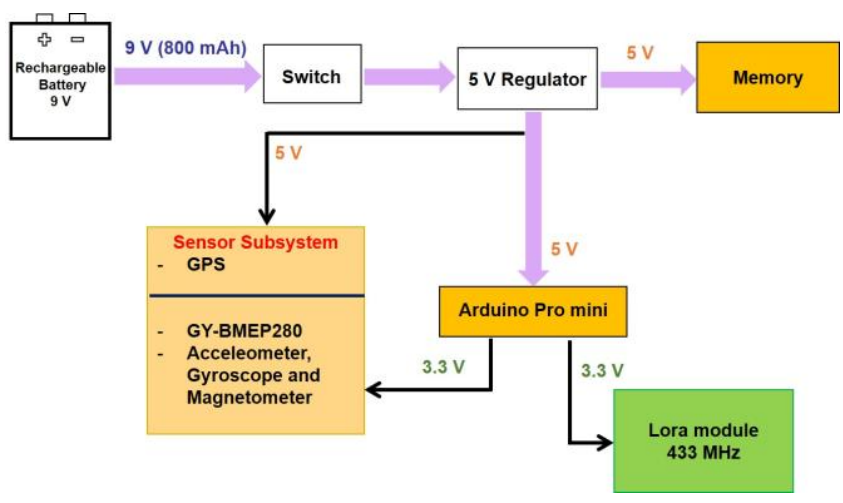

Fig. 2. Electrical subsystem diagram.

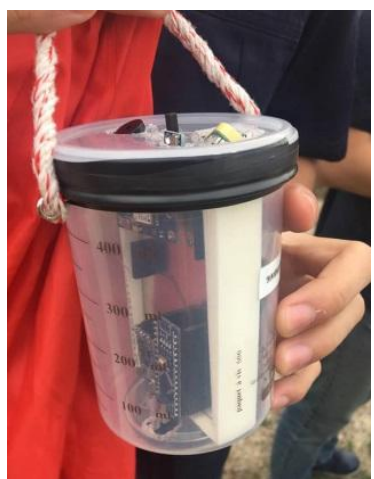

Fig. 3. The designed radiosonde configuration before a test.

Presently, the type of existing ground station used in Thailand is not suitable for receiving today's huge amount and diverse type of data from an advanced transmitter. For example, the existing ground station uses a very big antenna and is only able to receive data from only a single transmitter at one time, but the present technology dictates a need for a ground station to receive data from multiple sensors to get more precise data that will increase the effectiveness of the rainmaking operation. The cost of the existing system is also very high due to its having been imported from another country. This project also aimed to develop and manufacture new equipment within the country to reduce the average cost of investment and operate more effective than the existing system in order to better serve a variety of weather observation missions. 
This proposed ground station is shown in Fig. 4. It consists of an antenna, a tracking system, a receiver and a GUI interface. Two operational frequencies are utilized in this project: $2.4 \mathrm{GHz}$ by an Xbee module, aiming to operate at a low altitude of no more than $2 \mathrm{~km}$ and for drone operation; and $433 \mathrm{MHz}$ by LoRa module for high altitude use up to 15 $\mathrm{km}$ carried by a helium balloon. Both Xbee and LoRa receiver modules were supplied with power from a laptop.

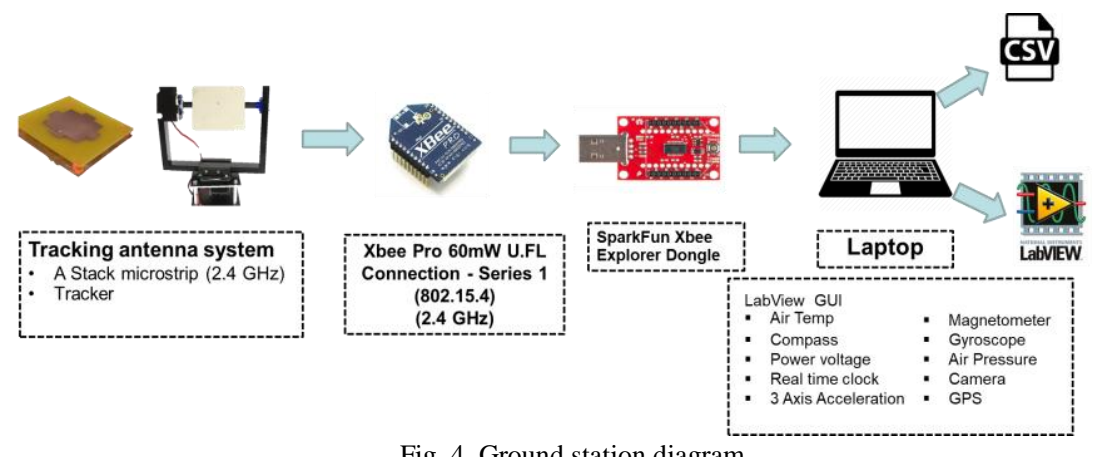

\section{1) Antenna}

Antenna is a significant part of a base station that can increase the efficiency of the system. Gain and pattern of antenna design are the priority consideration. This paper chose to design only a $2.4 \mathrm{GHz}$ antenna because of its merit of lightweight, compactness, portability and inexpensiveness. The stack microstrip antenna shown in Fig. 5 was made of FR4 dielectric substrate with a relative permittivity and loss tangent of 4.40 and 0.02 , respectively.
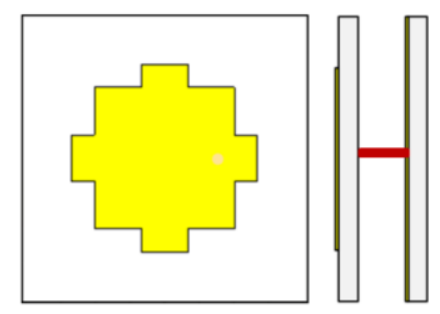

(a)

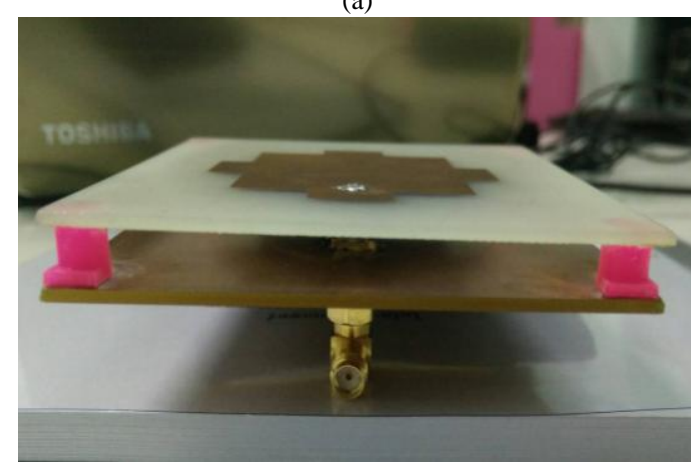

(b)

Fig. 5. A stack microstrip antenna (a) simulation (b) actual.

The simulated S11 of the antenna was lower than $-10 \mathrm{~dB}$ covering a frequency range from $2.38 \mathrm{GHz}$ to $2.56 \mathrm{GHz}$. The peak S11 was at $2.45 \mathrm{GHz}$. And the simulated radiation pattern was unidirectional with a gain of $8.31 \mathrm{dBi}$.

The measured results of the antenna are shown in Fig. 6. The S11 was better than the acceptable standard of $-10 \mathrm{~dB}$ meaning that this antenna was usable. The determined pattern was wider than the simulated pattern. The half power beamwidth was about 60 degrees. The measurement gain was $6.5 \mathrm{dBi}$.

\section{2) Tracking system}

Tracking system is a very important part to the operation of rainmaking because the receiver needs to receive weather information data from every desired altitude accurately. If we could get more and accurate weather data, it would be useful for successful rainmaking in the desired area. Due to rapid lifting up of helium balloon, the tracking system had to be able to automatically follow the helium balloon accurately. The structure of the tracking system was designed to be portable and lighter than the old system by using aluminium frame as shown in Fig. 7. This tracking system was designed to carry a load of antenna of about $1 \mathrm{~kg}$. The antenna might be a 2.4 $\mathrm{GHz}$ stack microstrip antenna or a $433 \mathrm{MHz}$ yagi antenna.

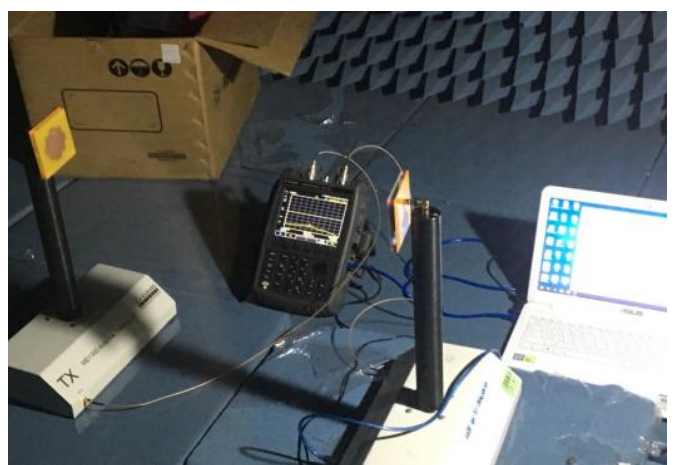

(a)

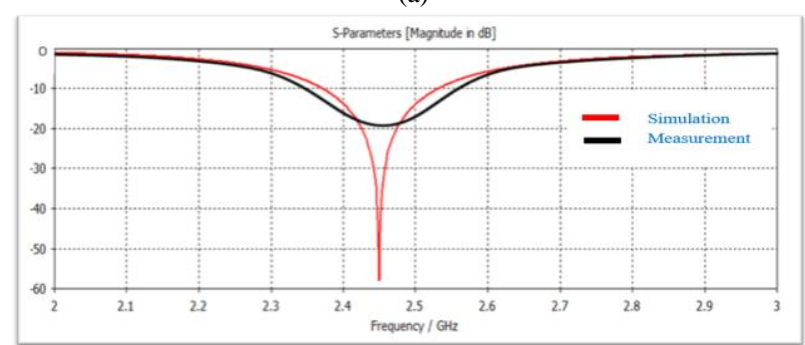

(b)

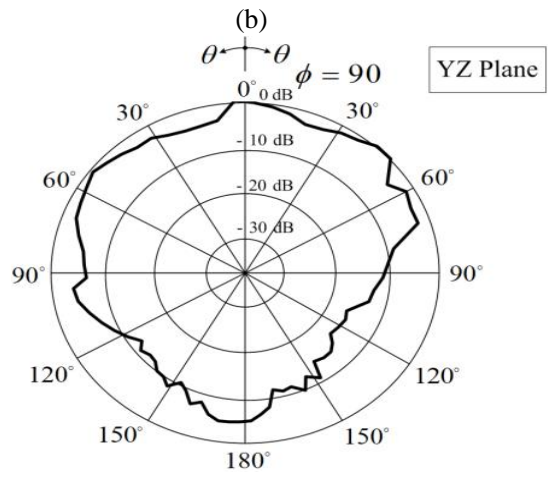

(c)

Fig. 6. Measurement results (a) chamber room test (b) S11 (c) pattern 


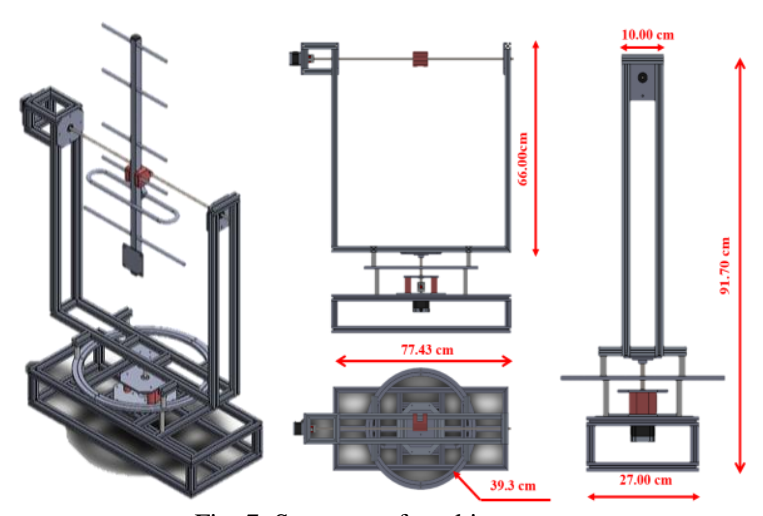

Fig. 7. Structure of tracking antenna.

This tracking system can be rotated 180 degrees around the vertical axis and 360 degrees around the horizontal axis by a step motor. To control the step motor, the tracking antenna system would be installed with Arduino, a GPS module, a compass sensor and an accelerometer sensor for calculating bearing angle and elevation angle between the location of the tracking antenna and the weather sensor equipment installed in the helium balloon. The motor of tracking system was supplied with power from a $24 \mathrm{~V} 7.2$ Ah battery for an operation time of about 2 hours.

\section{3) Display screen}

The display design used LabVIEW software program as the basic engineering tool that showed the data from each significant sensor in the transmitter equipment attached tof the balloon. The purpose of the design was for the easiest use by technicians and other non-engineers. The needed weather observation data were mainly surrounding weather parameters such as temperature, pressure and humidity, but in this project, the entire system was aimed to be a smart system hence a variety of sensors would be installed. Increasing the number of sensors means increasing weight, bandwidth and power requirement and complexity of the system, but it would be worthy to do so. Fig. 8 shows the designed screen with many data blocks consisting of date, time, GPS location from Google map, voltage level, compass direction, 3-axes acceleration and elevation speed. Each data block can be zoomed in and out freely. All sensor data would be displayed in real time when the system is operating and also after the operation was finished. The data would be stored in a format such as excel file format so that they were easy to access.

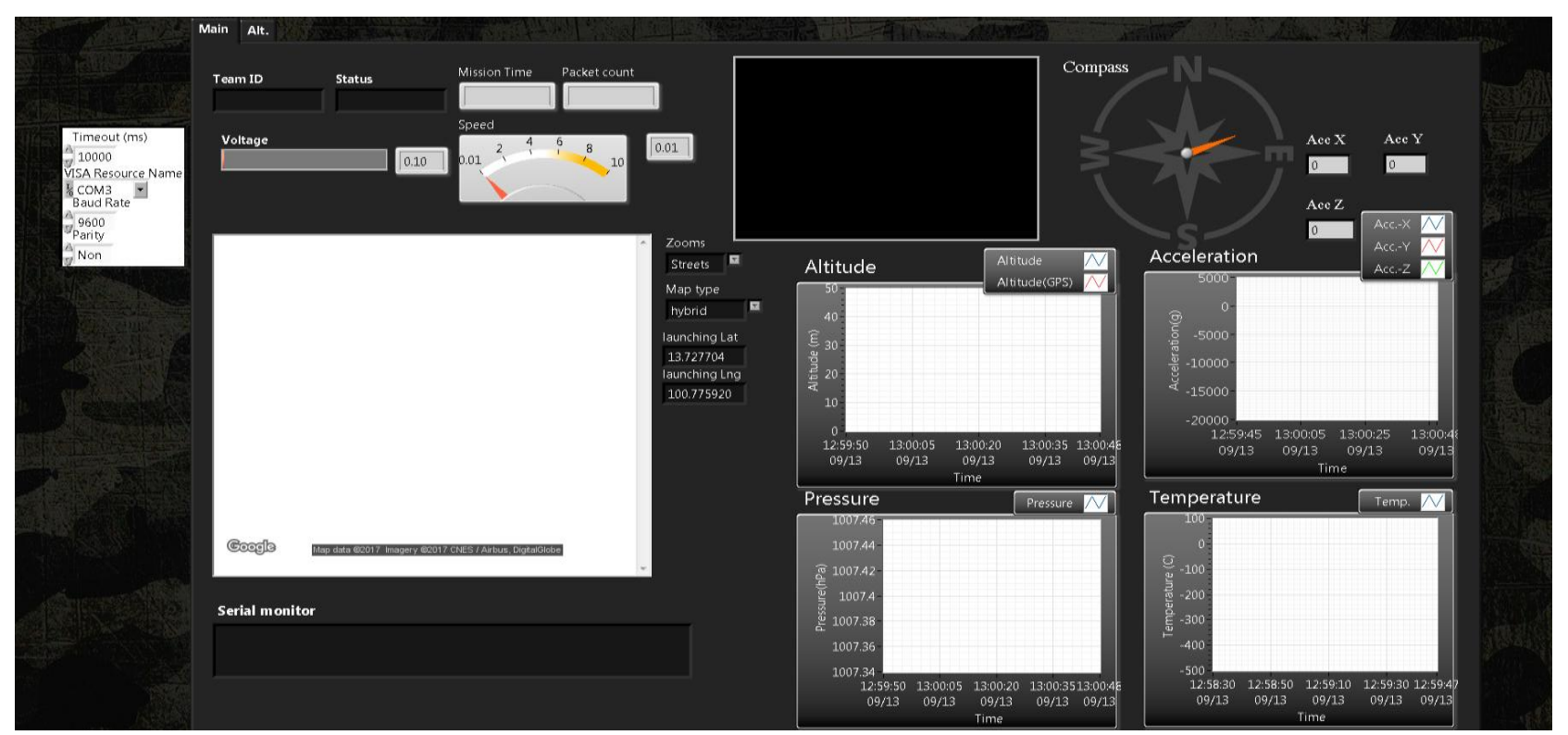

Fig. 8. Display screen.

\section{EXPERIMENTAL RESULTS}

To test the operation of this designed system, a balloon flight was suitable for testing from the ground up to a high altitude. However, a permission to release a balloon in an area was very difficult and complicated to get due to high plane traffic. Hence, we launched a balloon at two sites that have already been permitted to do so which belonged to the department of royal rainmaking and agricultural aviation. We also launched it at the same time that this department launched its balloon once a day.

The first balloon flight test was at Takli station. This site was at an uphill location about 400m above sea level. Fig. 9 shows the received weather data from about $400 \mathrm{~m}$ to almost $1200 \mathrm{~m}$ altitude to the base station. The comparative results between a current commercial radiosonde (the red straight line) and our designed radiosonde (the blue connected dots) shown in Fig. 9 are results of pressure and temperature data. It can be observed that the trends of the pressure data in Fig. 9(a) sensed by both radiosondes were almost exactly the same, while the temperature data obtained from the commercial radiosonde varied more than the data from our designed radiosonde because the sensor that we used was cheap and less sensitive (Fig. 9(b)).

The second balloon flight test was at Phimai station. This station was located at a usual drought area in Thailand. The environment of this area was an open space at sea level. It was really suitable as a test site. The operation altitude of this second test was up to $6 \mathrm{~km}$ because the sky was very clear on the test day. Our designed radiosonde was improved by an added humidity sensor. This sensor and several other sensors were arranged to be exposed directly to the open air. The results are shown in Fig. 10 (a-c): pressure, temperature and 
humidity. It was found that the measurements from our designed radiosonde were still not comparable to those from a commercial radiosonde, but it was operating well. Successful measurements were made from the ground level to the highest altitude tested. In the future, we will try to replace the inexpensive sensors with more capable and more expensive sensors and fully expect the new radiosonde to produce improved measurements.

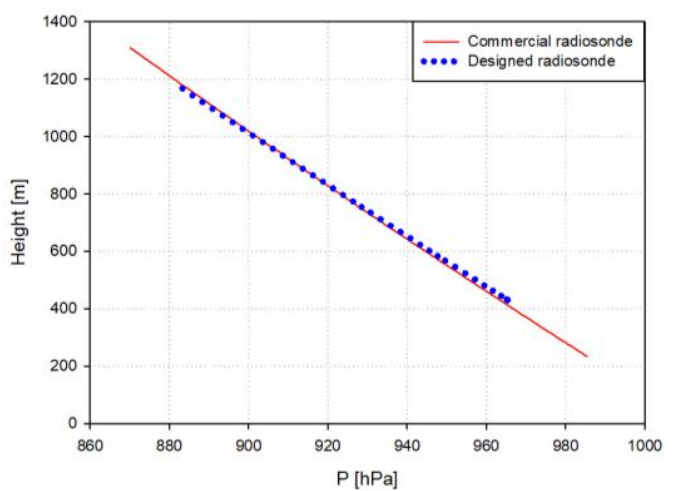

(a)

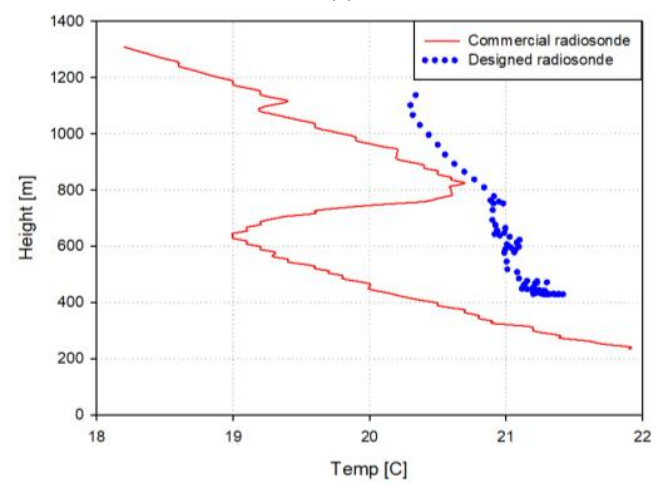

(b)

Fig. 9. Comparative weather sensor data between the two radiosondes at an altitude up to $1200 \mathrm{~m}$ (a) pressure (b) temperature.

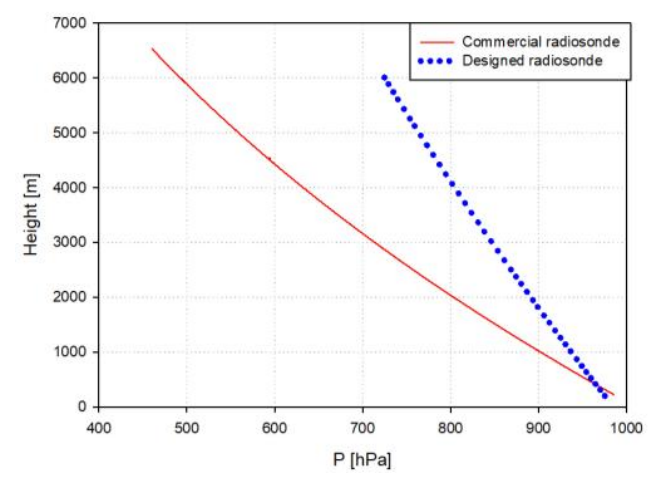

(a)

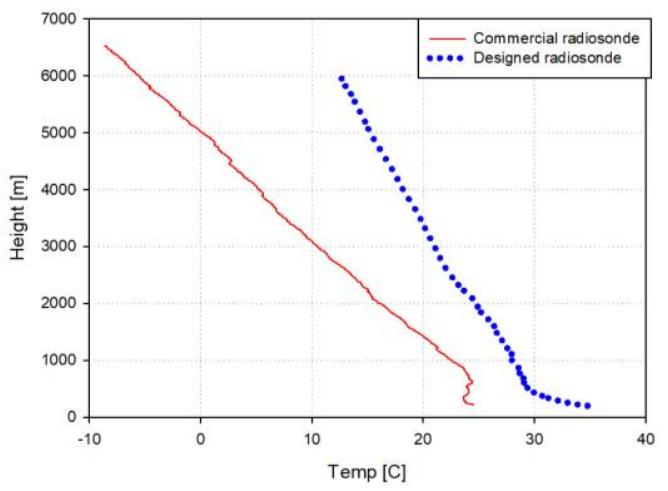

(b)

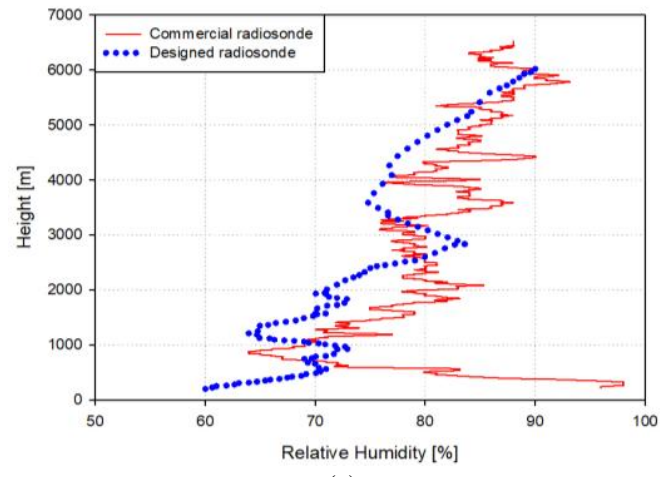

(c)

Fig. 10. Improved measurements from the designed radiosonde at a high altitude up to $6000 \mathrm{~m}$ (a) pressure (b) temperature (c) humidity.

We plan to test the designed radiosonde to acquire data at varying altitudes to cover rainmaking operation at $6-10 \mathrm{~km}$ above the ground several more times. Our next test will not only be limited to balloon flight but it may be attached to a drone for low altitude weather observation. In order for our designed radiosonde to be able to replace the current commercial one, we need to design into it a friendlier container and make it easy to operate by non-engineers.

\section{CONCLUSION}

This paper describes how to design a high and low altitude air observation system for a future advanced sensor network for rainmaking and weather observation. The radiosonde was improved by installing many weather, voltage, and GPS sensors to make the system more capable. The flow diagram of this ground station is almost the same with a station for other purposes. However, the specific purpose of a mission makes each system unique. Finally, this designed system is very valuable in reducing imports of foreign technologies and in enhancing the technology developed in the country.

In a future work, we aim to improve the design and implement it to a rainmaking system for use within the country. We plan to test our system several times and compare its performance with a commercial system in order to make sure that our developed system work effectively. The operation time was completely tested, but the altitude test was still not complete. We need to test whether the station can successfully receive data at $6-10 \mathrm{~km}$ range because a balloon mission for rainmaking operation will cover this kind of range.

\section{ACKNOWLEDGEMENTS}

The authors would like to thank King Mongkut's Institute of Technology Ladkrabang for providing the research grant [KREF046009] as well as the department of royal rainmaking and agricultural aviation for providing the test venue and the actual reference data.

\section{REFERENCES}

[1] B. K. MAndal, D. Bhattacharyya and S. Kang, "Attenuation of signal at a tropical location with radiosonde data due to cloud," Int. J. Smart Home, vol. 8, no. 1, pp. 15-22, 2014.

[2] Y. H. Kuo, W. S. Schreiner, J. Wang, D. L. Rossiter, and Y. Zhang, "Comparison of GPS radio soundings with radiosondes," Geophysical Research Letters, vol. 32, L05817, 2005. 
[3] V. O. John and S. A. Buehler, "Comparison of microwave satellite humidity data and radiosonde profiles: A survey of European stations," Atmos. Chem. Phys., vol. 5, pp. 1843-1853, 2005.

[4] M. W. Ryu, S. S. Lee, J. Yun, I. Y. Ahn, and H. W. Seok, "Design and implementation of a real-time radiosonde locatio system for upper-air observation," Smart Computing Review, vol. 4, no. 1, 2014.

[5] GPS-Based Measurement of Height and Pressure with Vaisala Radiosonde White Paper, Vaisala Oyj, 2013.

[6] R. Lehtinen, T. Tikkanen, J. P. Rasanen, and M. Turunen, Factors Contributing to RS41 GPS-Based Pressure and Comparison with RS92 Sensor-Based Pressure, TECO 2014.

[7] P. Survo, R. Lehtinen, and J. Kauranen, SI Traceability of Vaisala Radiosonde RS41 Sounding Data Calibration and Uncertainly Analysis, TECO, 2014.

[8] K. H. Kim, H. C. Bang, J. S. Chae, H. Y. Park, and S. H. Lee, "Ground station design for STSAT-3, 'Int'l J. of Aeronautical \& Space Sci, vol. 12, no. 3, pp. 283-287.

[9] T. Choi, T. H. Stevenson, and E. G. Lightsey, "Reference ground station design for university satellite mission with varying communication requirements," in Proc. 55th AIAA Aerospace Sciences Meeting, Jan. 9-13, 2017, Grapevine, Texas.

[10] R. M. R. Osorio, S. R. D. M. Coca, and F. R. Vedal, "Educational ground station based on software defined radio," in Proc. 59th International Astronautical Congress, 29 Sep.-3 Oct. 2008, Glasgow, UK.

[11] A. Done, A. M. Cailean, C. E. Lesanu, M. Dimian, and A. Graur, "Desing and implementation of a satllite communication ground station," in Proc. International Symposium on Signals, Circuits and Systems (ISSCS), July 13-14, 2017, Iasi, Romania.

[12] M. Bazdresch, S. Velayudhan, and W. Johnson, "A satellite ground station for teaching digital and wireless communications," in Proc. IEEE Frontiers in Education Conference (FIE), Oct. 12-15, 2016, PA, USA.

[13] R. H. Ma, Y. H. Wang, and C. Y. Lee, "Wireless remote weather monitoring system based on MEMS technologies," Sensors, vol. 11, pp. 2715-2727, 2011.

[14] A. Krauchi, R. Philipona, G. Romanens, D. F. Hurst, E. G. Hall, and A. F. Jordan, "Controlled weather balloon ascents and descents for atmospheric research and climate monitoring," Atmos. Meas. Tech., vol. 9, pp. 929-938, 2016.
[15] D. H. Kim, J. Y. Lim, and J. D. Kim, "Low-power, long-range, high-data transmission using Wi-Fi and LoRa," in Proc. 6th International Conference on IT Convergence and Security (ICITCS), Sep. 26-29, 2016, Prague, Czech Republic.

[16] M. Cattani, C. A. Boano, and K. Romer, "An experimental evaluation of the reliability of LoRa long-range low-power wireless communication," J. Sens. Actuator Netw., 2017, vol. 6, no. 7.

[17] G. Margelis, R. Piechocki, D. Kaleshi, and P. Thomas, "Low throughput networks for the iot: lessons learned from industrial implementations," in Proc. 2nd World Forum on Internet of Things (WF-IoT), Dec. 14-16, 2015, Milan, Italy.

[18] A. J. Wixted, P. Kinnaird, H. Larijani, A. Tait, A. Ahmadinai, and N. Strachan, "Evaluation of LoRa and LoRaWan for Wireless sensor networks," IEEE Sensors, 30 Oct-2 Nov. 2016, Orlando, Florida, USA

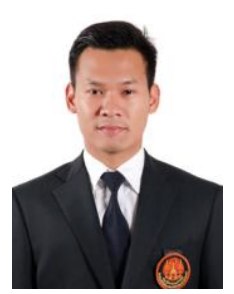

Peeramed Chodkaveekityada received $\mathrm{BE}$ and $\mathrm{ME}$ degrees in telecommunication engineering from the King Mongkut's Institute of Technology Ladkrabang, Bangkok, Thailand, in 2010 and 2012, respectively, and a $\mathrm{PhD}$ degree in aerospace engineering from the Tokyo Metropolitan University, Tokyo, Japan, in 2016. Currently, he is a lecturer at King Mongkut's Institute of Technology Ladkrabang. He was a satellite engineer at Thaicom Pcl from 2010 to 2013. His research interests are in satellite propagation, CanSat and CubeSat design.

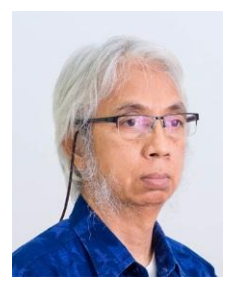

Paramote Wardkein received his $\mathrm{ME}$ and $\mathrm{PhD}$ degree in electrical engineering from King Mongkut's Institute of Technology Ladkrabang, Bangkok, Thailand in 1990 and 1997, respectively.

$\mathrm{He}$ is now an associate professor of Telecommunications Engineering Department, Faculty of Engineering, King Mongkut's Institute of Technology Ladkrabang. His current research interests include not only the field of signal processing but also analog-digital communications. 